\title{
Outcomes of Left Main Percutaneous Coronary Intervention
}

\author{
Muhammad Nasir Rahman, Bilal Hussain and Azmina Artani
}

\begin{abstract}
Objective: To study the outcomes of left main percutaneous coronary artery (LMCA) revascularisation.

Study Design: A descriptive study.

Place and Duration of Study: The Aga Khan University Hospital (AKUH), Karachi, from February till July 2016.

Methodology: The study included all adult patients aged 18 years or more, who underwent percutaneous LMCA revascularisation at study centre from April 2006 till April 2015. In-hospital outcomes were ascertained of patients via charts along with telephonic follow-up for outcome ascertainment at 1-year and 5-year. Results were expressed in terms of means and standard deviation for quantitative variables and percentages for qualitative variables.

Results: Of the 86 patients, the mean age was $66.05 \pm 12.6$ years and $69 \%$ (59 cases, $n=86$ ) of them were males. Sixteen $(18.6 \%)$ patients presented with cardiogenic shock and $17.4 \%$ (15 cases, $n=86$ ) required mechanical ventilation upon arrival. Among the 86 patients, 23.3\% (20 patients, $n=86$ ) underwent $\mathrm{PCl}$ because of unstable condition for CABG and refusal by the surgeons. Mean follow up time for participants was $40.5 \pm 25.7$ months with mean length of hospital stay of $4.36 \pm 2.4$ days. In-hospital mortality was $12.8 \%$, while mortality at 1 -year and at mean follow-up was $7.3 \%$ and $6.9 \%$, respectively.

Conclusion: LM percutaneous coronary intervention is a viable option for patients who are hemodynamicaly unstable and require urgent revascularisation or for patients denying bypass surgery due to other reasons in Pakistan. Prospective studies in future may be required to evaluate the role of $\mathrm{PCl}$ for $\mathrm{LM}$ lesions in elective setting in contrast to existing treatment options.
\end{abstract}

Key Words: Coronary artery disease, Percutaneous coronary Intervention, Coronary artery bypass grafting, Intravascular ultrasound, Left main coronary artery.

\section{INTRODUCTION}

Left main (LM) stenosis is visualised in around $3-5 \%$ of all coronary angiograms. ${ }^{1} \mathrm{~A}$ stenosis of more than $50 \%$ of the LM is associated with significant mortality as a critical LM lesion jeopardises at least $75 \%$ of the myocardium. ${ }^{2}$ The mainstay of treatment of left main stenosis has been coronary artery bypass grafting (CABG) with favourable outcomes reported in various studies. ${ }^{3-6}$

Since the inception of percutaneous coronary intervention $(\mathrm{PCl})$, multiple attempts have been made over the years to prove the equivalence of $\mathrm{PCl}$ to bypass surgery for treating left main interventions. Early attempts at $\mathrm{LM} \mathrm{PCl}$ with plain old balloon angioplasty (POBA) and bare metal stents showed appalling results. 7,8

Recently, data regarding LM PCI with newer generation drug eluting stents (DES) has emerged from all parts of the world and reviews suggest that in patients with severe LM disease, $\mathrm{PCl}$ with newer generation DES is comparable to CABG, and it offers an effective method of revascularisation with comparable long-term rates of

Department of Medicine, Section of Cardiology, The Aga Khan University Hospital, Karachi, Pakistan

Correspondence: Dr. Muhammad Nasir Rahman, Department of Medicine, Section of Cardiology, The Aga Khan University Hospital, Karachi, Pakistan

E-mail: nasir.rahman@aku.edu

Received: July 27, 2018; Accepted: December 15, 2018 major adverse outcomes. ${ }^{9-12}$ However, there is a dearth of data on clinical outcomes of left main $\mathrm{PCl}$ in Pakistan. This study is an effort to bridge this gap and put forward our experience of $\mathrm{LM}-\mathrm{PCl}$ practice at a tertiary health care centre in Pakistan.

The primary objective of this study was to determine the outcomes of $\mathrm{LM} \mathrm{PCl}$, both in hospital and post-discharge, in terms of mortality. The secondary objective of the study was to document angina, myocardial Infarction, repeat revascularisation, stroke and heart failure in patients who underwent LM PCl over an extended period of follow-up.

\section{METHODOLOGY}

The study was conducted at the Aga Khan University Hospital (AKUH), Karachi, from February till July 2016 after approval from the hospital Ethics Review Committee. The study included all adult patients aged 18 years or more who underwent percutaneous LMCA revascularisation at The Aga Khan University Hospital (AKUH), Karachi in the last decade from April 2006 till April 2015.

For the purpose of study, patients who had undergone left main coronary artery (LMCA) revascularisation percutaneously were identified using records from the AKUH cardiology catherisation laboratory records. Information relevant to study objectives were collected using a predesigned proforma. Information regarding procedural details, mortality and morbidity were collected from review of charts or via phone follow-up after seeking informed consent from the patients. 
The data were analysed using SPSS version 20.0 and results were expressed in terms of means and standard deviation for quantitative variables and frequency along with percentages for qualitative variables.

\section{RESULTS}

A total of 86 patients underwent $\mathrm{LM} \mathrm{PCl}$ at the study centre during the studied period. Amongst patients undergoing LM PCI, $62(72 \%)$ had unprotected LM. The most common presentation of patients undergoing LM PCI was unstable angina [40 patients (46.5\%)], 82 (95.3\%) had native $\mathrm{LM}$ disease requiring $\mathrm{PCl}$ of $\mathrm{LM}$, whereas $4.7 \%$ cases (4 patients) underwent $\mathrm{LM} \mathrm{PCl}$ as a bailout procedure. Mean follow-up duration was $40.5 \pm 25.7$ months.

Surgical opinion by cardiothoracic surgeon for CABG was sought for all patients prior to PCl. $23.3 \%$ (20 cases) patients were considered unfit for CABG because of hemodynamic instability, coexisting comorbidities, extremes of age or due to very high surgical risks. LM $\mathrm{PCl}$ was opted over CABG by patient or family in $(76.7 \%$ cases, 66 patients). LM PCI was primarily performed by the femoral route in $94 \%$ patients (80 cases). $79 \%$ (68 cases) had distal LM PCl done and $81 \%$ (70 cases) required $\mathrm{PCl}$ to other vessels in addition to LM. The Baseline characteristics of patients are given in Table I and procedural details of $\mathrm{PCl}$ are given in Table II.

The mortality at mean follow-up was $29 \%$ (25 patients), with the mean time to death of $20.12 \pm 27.9$ months. As autopsy was not performed in any case, all mortalities were presumed to be due to cardiovascular cause.

The in-hospital mortality was $12.8 \%$ (11 patients) with a mean hospital stay of $4.36 \pm 2.4$ days. All these patients

Table I: Baseline characteristics of the LM PCI patients.

\begin{tabular}{lc}
\hline Baseline characteristics & $\mathrm{N}(\%)$ \\
\hline No. of patients & 86 \\
\hline Age (years) & $66.05 \pm 12.6$ \\
\hline Male & $62(68.6)$ \\
\hline Unprotected LM & \\
\hline Risk factors & $79(91.8)$ \\
Hypertension & $42(48.8)$ \\
Dyslipidemia & $53(61.3)$ \\
Diabetes & $28(32.6)$ \\
Smoking & $14(16.3)$ \\
CKD & $6(7.0)$ \\
On Hemodialysis & $42(48.8)$ \\
LV Dysfunction & \\
\hline Presentation & $16(18.6)$ \\
STEMI & $30(34.9)$ \\
NSTEMI & $40(46.5)$ \\
Angina & $16(18.6)$ \\
Cardiogenic shock & $15(17.4)$ \\
Intubated patients & $8(9.3)$ \\
Cardiac arrest & CKD: Chronic kidney disease; LV dysfunction: EF <40\% at the time of PCl; STEMI: ST \\
elevation myocardial infarction; NSTEMI: Non ST elevation myocardial infarction. &
\end{tabular}

Table II: Procedure details of LM-PCI.

\begin{tabular}{lc}
\hline Procedure details & $\mathrm{N}(\%)$ \\
\hline Emergent PCI & $22(25.6)$ \\
\hline PCI of other vessels along with LM & $70(81.4)$ \\
\hline Type of stent in LM & $71(82.6)$ \\
Drug eluting stents & $13(15.1)$ \\
Bare metal stents & $1(1.2)$ \\
Covered stent & $1(1.2)$ \\
\hline Drug eluting balloon & \\
\hline Complications during PCI & $15(17.4)$ \\
Dissection & $3(3.5)$ \\
No reflow & $68(79.1)$ \\
\hline Distal LM PCI & $18(20.9)$ \\
\hline Ostial LM PCI & \\
\hline PCI Technique & $42(48.8)$ \\
LM to LAD crossover & $8(9.4)$ \\
SKS & $4(4.7)$ \\
CULOTTE & $8(9.4)$ \\
LM to LCX crossover & $23(26.7)$ \\
LM Stenting only & $30(34.9)$ \\
\hline IVUS & $20(23.3)$ \\
\hline IABP placement & $14(16.3)$ \\
\hline TPM placed & $19(22.1)$ \\
\hline Inotropic support &
\end{tabular}

LM: Left main; $L A D$ : Left anterior descending artery; $L C x$ : Left circumflex artery; PCI: Percutanoeus coronary intervention; IVUS: Intravascular ultrasound; IABP: Intra aortic balloon pump; TPM: Temporary pacemaker; SKS: Simultaneous kissing stenting; TPM: Temporary pacemaker.

had unprotected LM PCI. The mean age was $69.7 \pm 11.3$ years. Nine patients had been deemed unfit for CABG due to hemodynamic instability as they were in cardiogenic shock requiring intubation, inotropic support and counter pulsation therapy with intra-aortic balloon pump. The major cause of in-hospital mortality was refractory cardiogenic shock (5 patients), other causes included overwhelming sepsis and GI bleeding. Among the 75 patients that were discharged from the hospital, the mortality at one year was $6.6 \%$ (5 patients).

Distal LM stenting poses a unique challenge as it is equivalent to bifurcation stenting. In this study, 68 patients $(79.1 \%)$ underwent $\mathrm{PCl}$ to distal LM. The total mortality for distal LM PCl at mean follow-up was $23.2 \%$ (20 patients). The in-hospital mortality of patients undergoing distal LM PCI was $10.4 \%$ (09 patients). $4.6 \%$ (04 patients) undergoing distal LM PCl required target lesion revascularisation, whereas no patient undergoing $\mathrm{PCl}$ to LM ostium or shaft required TLR.

IVUS was performed in 30 patients $(34.9 \%$ cases $)$ undergoing $\mathrm{LM} \mathrm{PCl}$, on follow-up 7 (8.13\%) mortalities were identified. Nineteen $(22.09 \%)$ cases, who underwent IVUS at the time of LM PCl, were alive at follow-up, whereas 4 cases were lost to follow-up.

At mean follow-up from index procedure, 10 (11.6\%) patients had MI, $4(4.6 \%)$ patients required repeat target lesion revascularisation, and $7(8.13 \%)$ patients had congestive heart failure. No patient had stroke. All patients alive at mean follow-up were compliant to dual antiplatelet therapy with aspirin and clopidogrel. 
Amongst the 10 patients who had MI, distal LM PCl was performed in $9(10.4 \%)$ patients with bifurcation stenting of distal LM done in $4(4.6 \%)$ patients and left main to LAD crossover was done in $5(5.8 \%)$ patients. Four $(4.6 \%)$ patients showed in-stent restenosis (ISR) in left main stent on subsequent angiograms. All patients developing ISR had distal LM stenting with LM-LAD crossover technique applied in two patients and bifurcation stenting done in two patients. All patients developing ISR had DES implanted with a mean diameter of $3.13 \pm 0.47 \mathrm{~mm}$ with post-dilatation performed with a mean balloon size of $3.0 \pm 0.40 \mathrm{~mm}$.

\section{DISCUSSION}

The treatment of choice for critical left main disease is CABG. The current guidelines, in light of published literature, also endorse CABG for LM disease as a class I recommendation. However, the guidelines also take into consideration the option of $\mathrm{LM} \mathrm{PCl}$ an alternative therapeutic option for left main disease in patients who are either not suitable for surgical re-vascularisation, ${ }^{13}$ or decline CABG.

Recent literature shows that $\mathrm{PCl}$ is non-inferior to $\mathrm{CABG}$ for the treatment of left main disease. 10-15 This success of $\mathrm{PCl}$ to LM is attributed primarily to the introduction of newer generation DES and the use of dual anti-platelet therapy. The advent of drug eluting stents has a significant impact on the outcomes of left main stenting, as several registries regarding LM stenting with DES have shown positive results in terms of efficacy and safety profile.

The present study reported a mortality of $29 \%$ at mean follow-up. This inflated figure could be explained by the fact that among the cases undergoing $\mathrm{LM} \mathrm{PCl}$ at our centre, most of the patients were elderly (mean age 66 \pm 12.5 years), in cardiogenic shock at the time of $\mathrm{PCl}$ $(18.6 \%)$ and deemed unfit for CABG (23.3\%).

Unprotected left main $\mathrm{PCl}$ (UPLM PCl) is an option employed mostly in emergency situations that preclude an invasive option. Therefore, outcomes are also affected by the adverse clinical presentation rather than the procedure itself. Unprotected LM (UPLM) has been identified as an important predictor of mortality in previous studies. ${ }^{16-18}$ In this study, mortality in UPLM was $23.2 \%$. An explanation for this high rate MACE is the fact that $81.25 \%$ of patients who had UPLM PCI also had significant disease of a non-LM vessel requiring intervention. The high occurrence of adverse events in this group can be attributed to the inherent heavy atherosclerotic burden.

The mortality of distal LM PCI was $23.2 \%$ (20 patients) with ISR seen in $4.5 \%$ of patients undergoing repeat angiograms. This experience of distal $L M P C l$ was comparable to the reported literature that suggests that $\mathrm{PCl}$ of lesions involving the ostium or shaft of LM are associated with better outcomes. 19,20 Similarly, studies have reflected that $\mathrm{PCl}$ for distal LM lesions is the most significant predictor of repeat revascularisation and overall MACE. 21 The high mortality among distal LM PCI patients can be attributed to the complex anatomy of distal LM.

The usage of smaller size stents in the left main may be attributed to diffuse disease in left main system. However, as there exists no reference values from our population on minimal surface area (MSA) and minimal luminal diameter of left main, subjective assessment of the operators emerges as the plausible rationale for this discrepancy. Although it has been recognised in the EXCEL trial that a small final MSA measured by IVUS after LM-PCl has a strong association with adverse events during long-term follow-up. 22

The main limitation of this study is its retrospective design. As all the patients did not have angiographic follow-up, the true rate of restenosis of LM could not be determined. Thirteen patients were lost to follow-up and no data could be retrieved for these patients.

\section{CONCLUSION}

Though CABG is the preferred choice of treatment for LM lesions, $\mathrm{PCl}$ of left main coronary artery is an option primarily reserved for those patients who require urgent revascularisation due to hemodynamic instability. Due to the anatomical location of LM lesions and the complexity of $\mathrm{PCl}$ in left main, there is a significant chance of restenosis. Planned, and elective $\mathrm{PCl}$ of LM lesions performed under IVUS guidance have better outcomes, with reduced rates of restenosis and MACE. Further prospective studies are required to evaluate the role of $\mathrm{PCl}$ for LM lesions in elective setting.

\section{REFERENCES}

1. Stone PH, Goldschlager N. Left main coronary-artery diseasereview and appraisal. Cardiovascular Medicine 1979; 4:165.

2. Kalbfleisch $\mathrm{H}$, Hort W. Quantitative study on the size of coronary artery supplying areas postmortem. Am Heart J 1977; 94:183-8.

3. Taggart DP, Kaul S, Boden WE, Ferguson TB, Guyton RA, Mack MJ, et al. Revascularization for unprotected left main stem coronary artery stenosis stenting or surgery. J Am Coll Cardiol 2008; 51:885-92.

4. Sabik JF, Blackstone EH, Firstenberg M, Lytle BW. A benchmark for evaluating innovative treatment of left main coronary disease. Circulation 2007; 116(11 suppl):I232-9.

5. Yusuf S, Zucker D, Peduzzi P, Fisher LD, Takaro T, Kennedy JW, et al. Effect of coronary artery bypass graft surgery on survival: Overview of 10-year results from randomised trials by the coronary artery bypass graft surgery trialists collaboration. Lancet 1994; 344:563-70.

6. Mäkikallio T, Holm NR, Lindsay M, Spence MS, Erglis A, Menown IB, et al. Percutaneous coronary angioplasty versus coronary artery bypass grafting in treatment of unprotected left main stenosis (NOBLE): A prospective, randomised, openlabel, non-inferiority trial. Lancet 2016; 388:2743-52. 
7. O'Keefe JH, Hartzler GO, Rutherford BD, McConahay DR, Johnson WL, Giorgi LV, et al. Left main coronary angioplasty: Early and late results of 127 acute and elective procedures. Am J Cardiol 1989; 64:144-7.

8. Park SJ, Park SW, Hong MK, Lee CW, Lee JH, Kim JJ, et al. Long-term (three-year) outcomes after stenting of unprotected left main coronary artery stenosis in patients with normal left ventricular function. Am J Cardiol 2003; 91:12-6.

9. Valgimigli M, van Mieghem CA, Ong AT, Aoki J, Granillo GA, McFadden EP, et al. Short-and long-term clinical outcome after drug-eluting stent implantation for the percutaneous treatment of left main coronary artery disease: Insights from the rapamycin-eluting and taxus stent evaluated at rotterdam cardiology hospital registries (RESEARCH and T-SEARCH). Circulation 2005; 111:1383-9.

10. Serruys PW, Morice MC, Kappetein AP, Colombo A, Holmes DR, Mack MJ, et al. Percutaneous coronary intervention versus coronary-artery bypass grafting for severe coronary artery disease. N Engl J Med 2009; 360:961-72.

11. Stone GW, Sabik JF, Serruys PW, Simonton CA, Généreux $P$, Puskas $\mathrm{J}$, et al. Everolimus-eluting stents or bypass surgery for left main coronary artery disease. $N$ Engl J Med 2016; 375: 2223-35.

12. Avula HR, Rassi AN. The current state of left main percutaneous coronary intervention. Curr Atheroscler Rep 2018; 20:3.

13. Levine GN, Bates ER, Blankenship JC, Bailey SR, Bittl JA, Cercek $B$, et al. ACCF/AHA/SCAI guideline for percutaneous coronary intervention: executive summary: A report of the American College of Cardiology Foundation / American Heart Association Task Force on practice guidelines and the society for cardiovascular angiography and interventions. Circulation 2011; 124:2574-609.

14. Naik H, White AJ, Chakravarty T, Forrester J, Fontana G, Kar S, et al. A meta-analysis of 3,773 patients treated with percutaneous coronary intervention or surgery for unprotected left main coronary artery stenosis. JACC Cardiovasc Interv 2009; 2:739-47.
15. Seung KB, Park DW, Kim YH, Lee SW, Lee CW, Hong MK, et al. Stents versus coronary-artery bypass grafting for left main coronary artery disease. N Engl J Med 2008; 358:1781-92.

16. Cavalcante R, Sotomi Y, Lee CW, Ahn JM, Farooq V, Tateishi H, et al. Outcomes after percutaneous coronary intervention or bypass surgery in patients with unprotected left main disease. J Am Coll Cardiol 2016; 68:999-1009.

17. Boudriot $E$, Thiele $H$, Walther $T$, Liebetrau $C$, Boeckstegers $P$, Pohl $\mathrm{T}$, et al. Randomized comparison of percutaneous coronary intervention with sirolimus-eluting stents versus coronary artery bypass grafting in unprotected left main stem stenosis. J Am Coll Cardiol 2011; 57:538-45.

18. Biondi-Zoccai GG, Lotrionte M, Moretti C, Meliga E, Agostoni P, Valgimigli $\mathrm{M}$, et al. A collaborative systematic review and metaanalysis on 1,278 patients undergoing percutaneous drugeluting stenting for unprotected left main coronary artery disease. Am Heart J 2008; 155:274-83.

19. Palmerini T, Sangiorgi D, Marzocchi A, Tamburino C, Sheiban I, Margheri $\mathrm{M}$, et al. Ostial and midshaft lesions vs. bifurcation lesions in 1111 patients with unprotected left main coronary artery stenosis treated with drug-eluting stents: Results of the survey from the Italian society of invasive cardiology. Eur Heart $J$ 2009; 30:2087-94.

20. Chieffo A, Park SJ, Valgimigli M, Kim YH, Daemen J, Sheiban I, et al. Favorable long-term outcome after drug-eluting stent implantation in nonbifurcation lesions that involve unprotected left main coronary artery: A multicenter registry. Circulation 2007; 116:158-62.

21. Gershlick AH, Kandzari DE, Banning A, Taggart DP, Morice MC, Lembo $\mathrm{NJ}$, et al. Outcomes after left main percutaneous coronary intervention versus coronary artery bypass grafting according to lesion site: Results from the EXCEL trial. JACC Cardiovasc Interv 2018; 11:1224-33.

22. Maehara A, Mintz G, Serruys P, Kappetein A, Kandzari D, Schampaert $\mathrm{E}$, et al. Impact of final minimal stent area by IVUS on 3-year outcome after $\mathrm{PCl}$ of left main coronary artery disease: The EXCEL trial. J Am Coll Cardiol 2017; 69 (11 Supplement):963. 